\title{
STUDY OF DISEASES RISK AT KHIRBA SAMRA TREATMENT PLANT BY GIS \& RS TECHNIQUES
}

Dr. O. Dhaimat and Dr S. Dhaisat ${ }^{2}$

1 Associate professor in ISRA University, Jordan

2 Associate professor in RJGC Collage, Jordan

(Received July 10, 2007 Accepted December 12, 2007)

Wastewater treatment plants are proper means for collecting, analysis, and producing solid and liquid portions of wastewater that coming from houses, industries, floods, or other activities of human kind according to certain standards followed by local, regional, or global authorities. The sequence of wastewater treatment includes physical, chemical, and biological processes. But unfortunately, some times these plants become major resources of pollution and diseases, if they don't follow the means properly. The present study was carried out with that example of wastewater treatment plants which causes a lot of problems and side effects towards village of Khirba Samara and surrounded area, even with other communities and population of Jordan territory.

KEYWORDS:Remote sensing, Geographical Information System, Khirba Samra, treatment plant, pollution, diseases, and side effects.

\section{INTRODUCTION}

Water as a vital substance for human life is never be found pure one hundred percent through its journey in the nature or within various activities of mankind due to the presence of impurities. The load or the type of these pollutants plays major role for its given name, use, and side effects.

The normal procedure of decreasing or removing such contaminations needs knowledge about samples collection means of examination and treatment methods. The resultant may give guide for showing the types and amount of available diseases, such as malaria and colira, which have direct effect and challenge towards the human beings; particularly in the communities where mosquitoes transmit diseases from shallow water and treatment plants through uncovered pipes and open channels.

In order to study the available diseases or to check its power or its side effect, it needs to follow certain types of detecting means, which may differ in concept or methodology.

The scope of this paper is to prove various effects or risks of such diseases by using remote sensing (RS) and geographic information system (GIS) techniques. The combination use of these techniques provides strong tools for monitoring environmental conditions that are suitable for such diseases and how much that risk of disease transmitted towards population. In other words, image data and other information can be expressed within certain layers of graphical representation which related to these diseases that spread towards various villages and communities of 
population surrounding the treatment plant; especially those which are suffering from the low medical care, education, and small rate of income.

\section{STUDY AREA}

As shown in Fig1, khirba samra treatment plant is located at distance of $15 \mathrm{~km}$ north east of Zarqa city in Jordan, and the surrounded lands consist of swamps, wetlands, and vegetation farms, which are found along the passage of wastewater discharge to or from that plant.

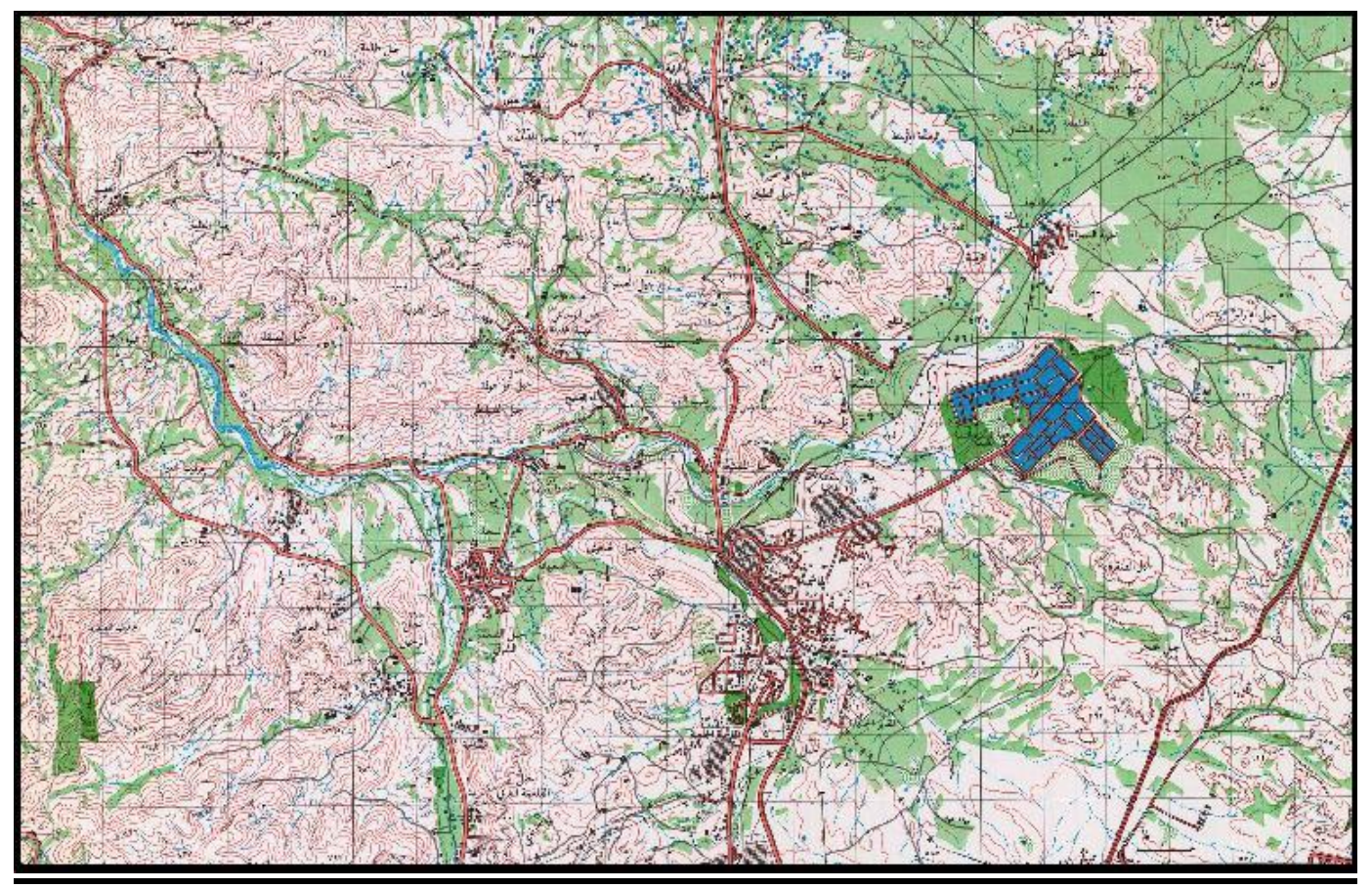

Fig 1. Location of treatment plant

Most of the command area is flat with elevation about $600 \mathrm{~m}$ above sea level. Also, a number of small attributes of Sail Zarqa are available at that area. Besides that, swamps and seasonal plants are grown up during the winter season as well as summer season. These conditions are suitable for growth of mosquitoes and other flying insects during the whole year.

\section{DATA COLLECTION AND METHODOLOGY}

Satellite images, topographic maps, land use maps, rainfall maps, soil maps, as well as agricultural maps were used as resources of data acquisition, analysis, and production.

By combining images with topographic maps we can derive a number of layers which are necessary for the sequence of events of this research. Fig 2 represents the maps of average rainfall over the command area. 


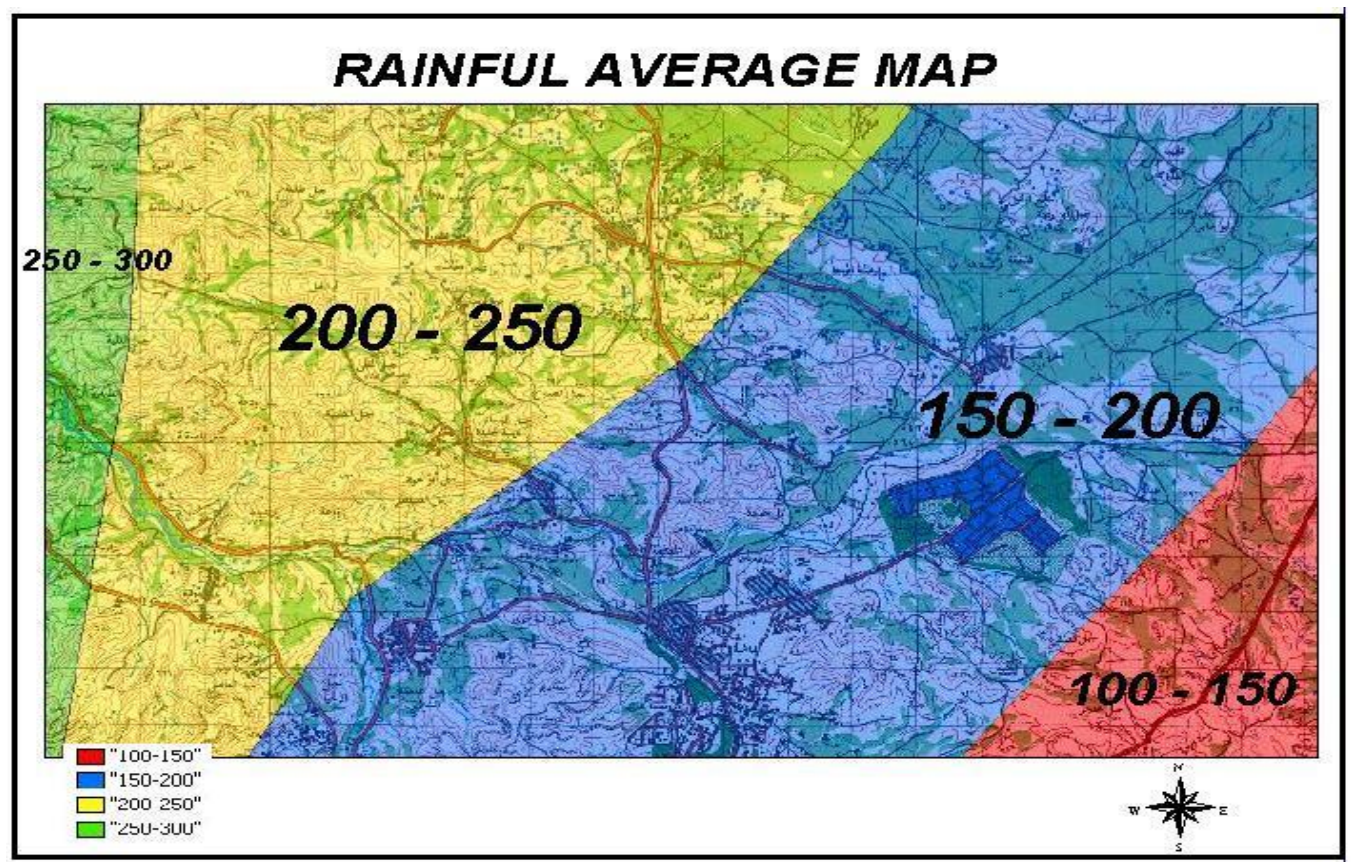

Fig 2: Rainfall Average Map

Figure 3 shows the pollution spread by the wastewater at the treatment plant and Sail zarqa.

Figure 4 expresses the effect of pollution of wastewater of treatment plant towards near communities and villages.
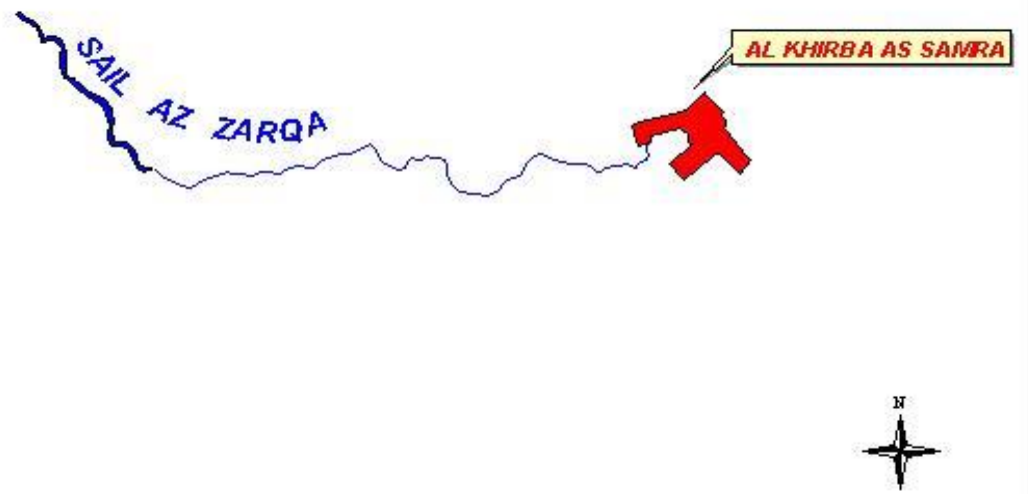

Fig 3. Map of treatment plant and sail zarqa 


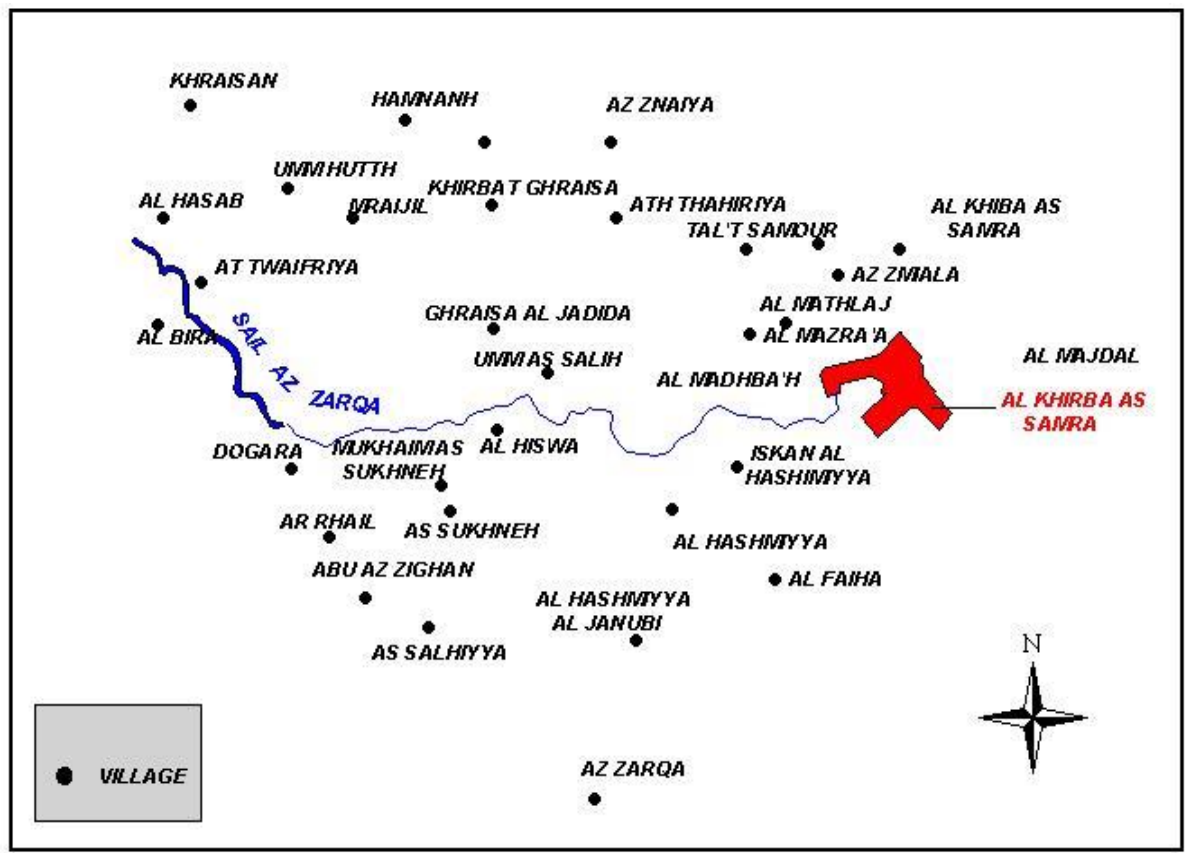

Fig 4. Villages around treatment plant

Figure 5 indicates the side effects of wastewater onto the land cover and land use around the treatment plant.

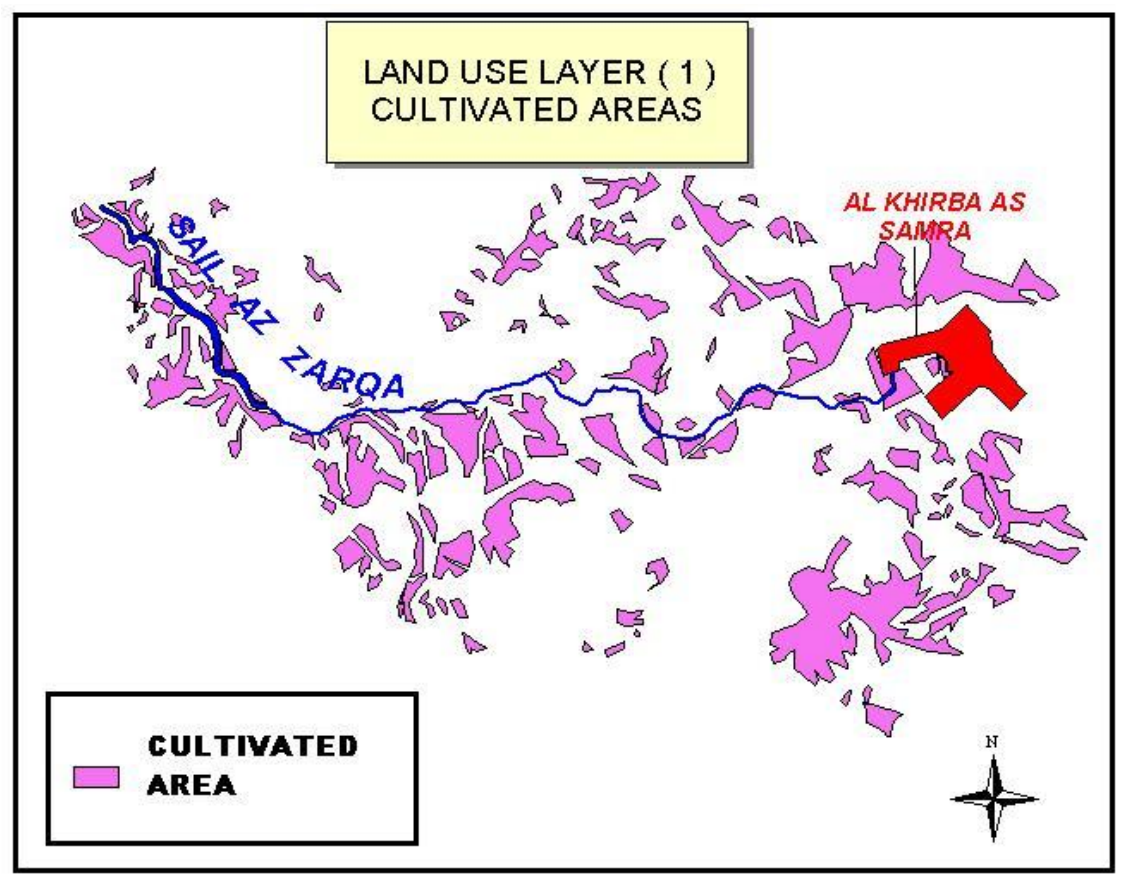

Fig 5.Land use map around treatment plant 


\section{ANALYSIS}

In order to study the role of previous parameters, it was found that the isolated houses and communities which were located within $5 \mathrm{~km}$ radius around the treatment plant were suffered from some diseases; such as malaria and colira, which were transformed by mosquitoes and flying insects. The resultant is creating a risk area related to the effects of such diseases as shown in figure 6. This situation needs cooperation and coordination between various departments involving health, environment, agriculture, water, and planning in order to decrease the available side effects and to prevent that in the future also.

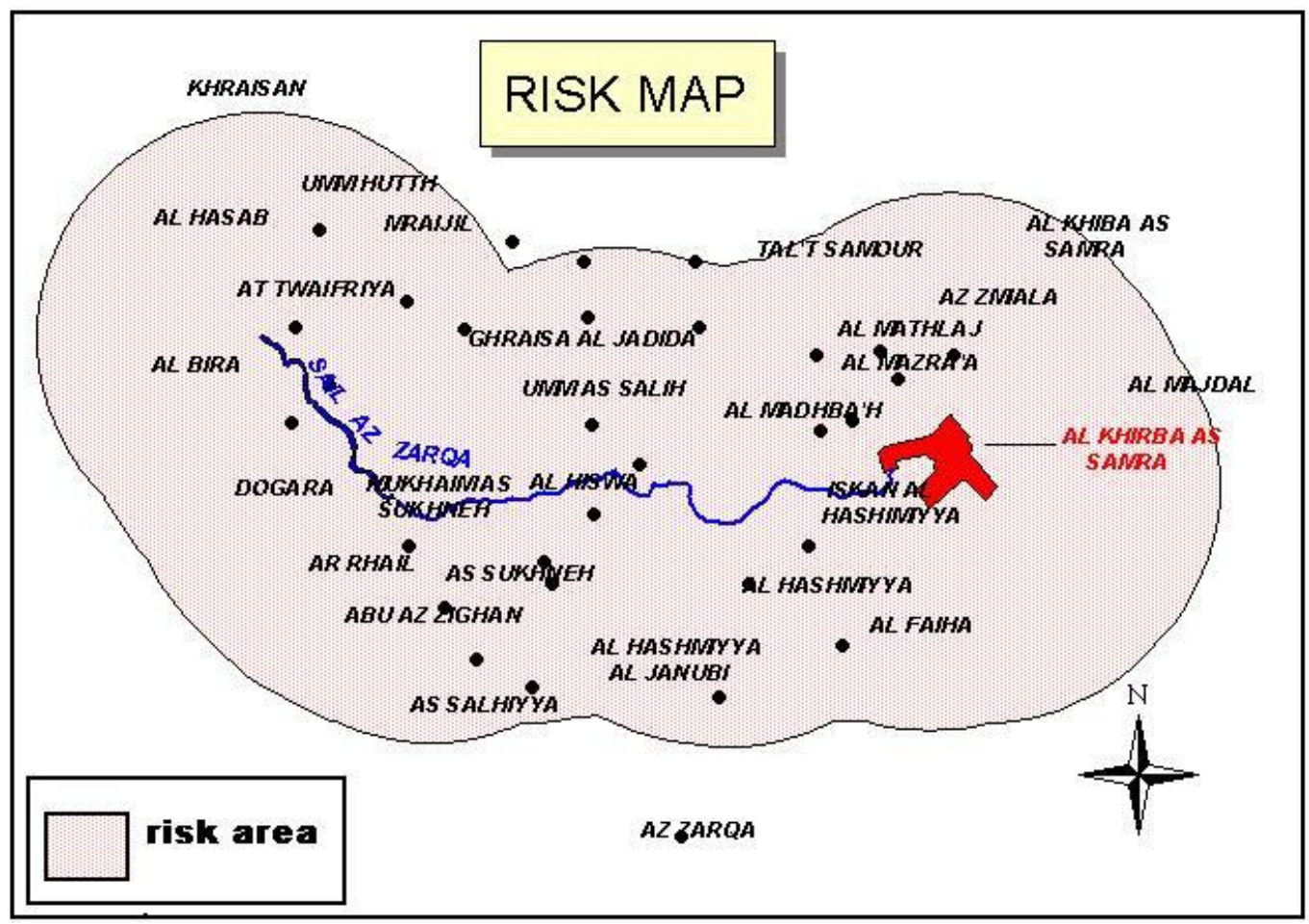

Fig 6. Risk area of disease effect of pollution

Besides that, the trees of fruit; especially apples and lemons that are grown in the area play important role in the aspects of environmental pollution and disease transmission towards human being, because they are sometimes irrigated from wastewater during summer season due to the shortage of water resources. Besides that, high temperature is domain within the command area, which increases the growth of microorganisms more and more.

These conditions need a certain policy in order to supply water for these trees in one hand, and to prevent growth of diseases in other hand. Fig7 represents the distribution of the polluted fruit trees around the treatment plant. 


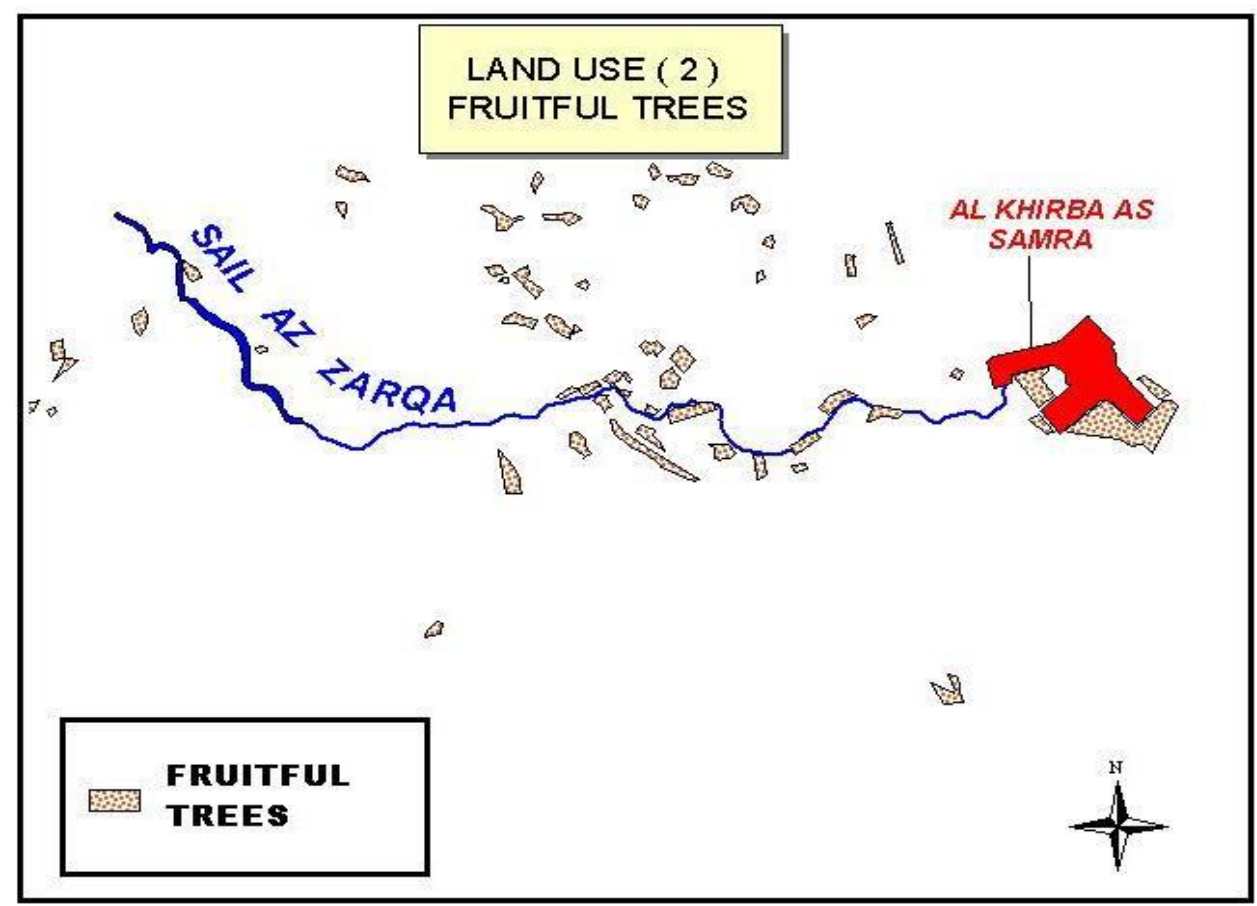

Fig7. Fruit trees around treatment plant

In addition to that, lands which used for vegetation growth are considered a good home for pollution and diseases towards human kind within communities, villages and towns, which are located in the risk area, where diseases are spread fast directly between human communities or through vegetables or fruits that are grown in the same area as shown in figure 8 .

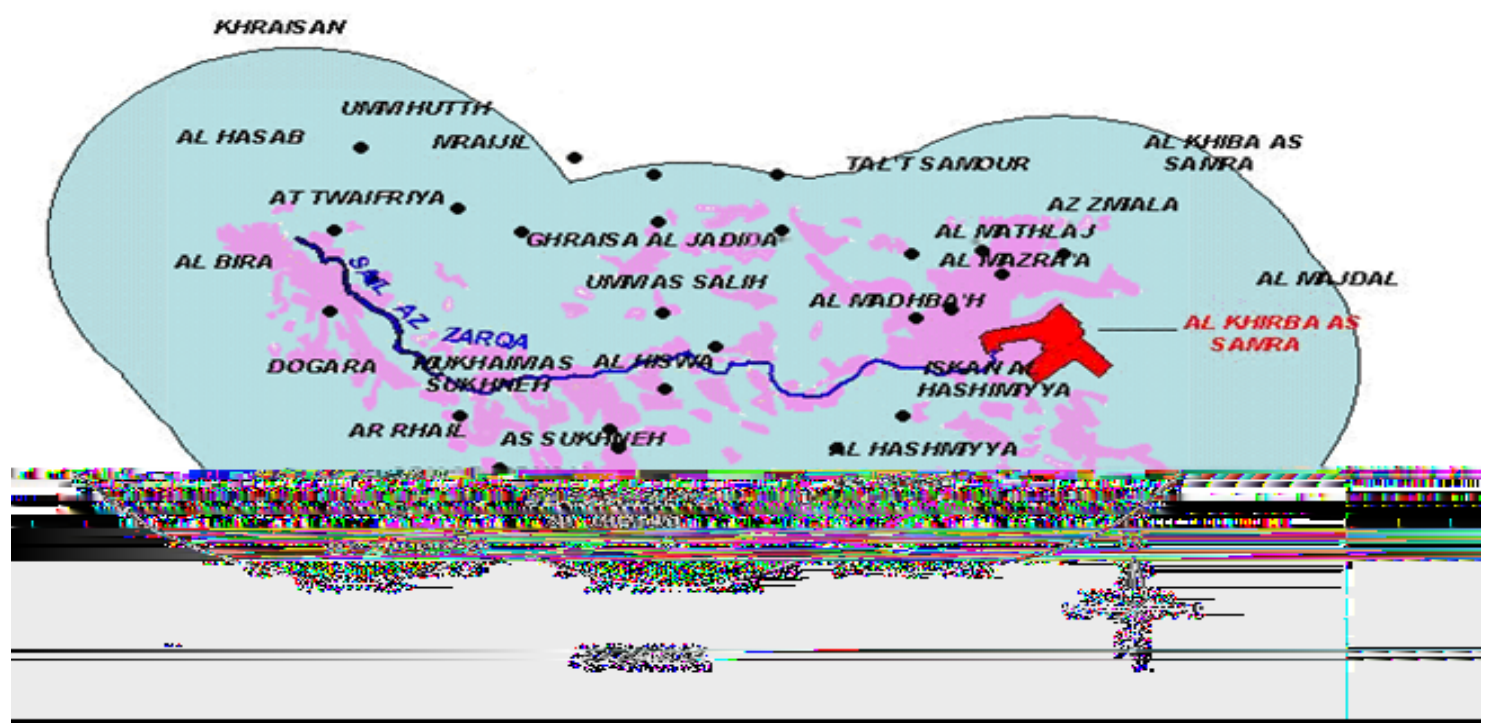

Fig 8: Effect of pollution at risk area 
Furthermore, the small amount of rainfall within command area dictates the need of irrigation for plant growth by water or wastewater, which creates a big problem for health, society, and economy towards the population in close areas of treatment plant or for those which are away from the treatment plant, due to the transmission of such diseases during handling, selling, and purchasing of these crops among various positions in the country.

\section{CONCLUSION}

As shown in the previous steps and figures, images supported by maps and other resources of data identified a number of parameters through a set of layers by using GIS technique in order to show the assessment of wastewater at khirba samra plant towards mankind, plants, and environment around that plant.

Out of the previous parameters, diseases play major side effects from treatment plant, untreated wastewater, vegetation and fruit trees that are irrigated by the wastewater of treatment plant, or along sail Zarqa.

Beside that, it is fruitful to take care so much about wastewater site selection, means and tools that are used for treatment processing in order to avoid pollution side effects.

Besides that, data bank, means of technology, and specific methods are proper tools for taking precautions, diagnose, and treatment of various micro- organisms and other contamination resources at or around treatment plant. This requires a cooperation and coordination of related departments in order to prevent or decrease the side effects of such contaminations within command area.

\section{REFRENCES}

1.M.C.J. Damen, Remote sensing for resources development and environmental management, ITC, Netherlands, 1986.

2.H. Ebner et.al, Spatial information from digital photogrammetryand computer vision, 1994.

3. Elias salameh, Water quality degradation in Jordan, 1996.

4.Elias salameh \& Helen Bannayan, Water resources of Jordan present status and future potentials, Amman ,1993

5. Friedrich ebert stiftung, Water pollution in Jordan, causes and effects, Amman, Jordan, 1991.

6.Hammer, Viessman and Clark, Water Supply and Pollution Control, London, 1999

7. International Archives at photogrammetry and remote sensing, volume 28, Tsu Kuba, Japan, 1990.

8. M. Meneti, physical aspect and determination of evaporation in deserts, applying remote sensing techniques, 1984.

9. Metcalf \& Eddy, "wastewater engineering treatment disposal reuse", Mc Grew hill publishing company, New Delhi, 1979. 
Study of Diseases Risk of Khirba Samra Treatment Plane by GIS and RS Techniques

Dr. O.Dhaimat and Dr.S. Dhaisat

\section{دراسة مخاطر الأمراض لمحطة المعالجة بالخربة السمراء بواسطة تقنيات GIS و RS}

تعتبر محطات التتقية الوسائل المناسبة لجمع وتحليل وإخراج المواد الصلبة والسوائل من المياه العادمة من المساكن، المصانع، الفياضانات ومختلف النشاطات الإنسانية وضمن المعايير المعتددة محلياً وإقليميا ودولياً.

تتضمن معالجة المياه العادمة وسائل فيزيائية وكيميائية وبيولوجية، لكنه لسوء الحظ تعتبر هذه المحطات وسائل للتلوث البيئي والأمراض أن لم تتم تلك المراحل بالثكل المطلوب.

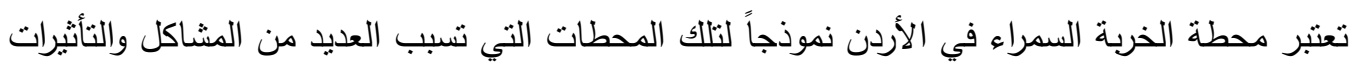

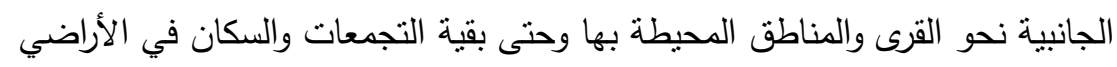

